\title{
Serotonin in the Developing Stomatogastric System of the Lobster, Homarus americanus
}

\author{
Kathryn S. Richards, ${ }^{1,3, *}$ David J. Simon, ${ }^{1}$ Stefan R. Pulver, ${ }^{1}$ Barbara S. Beltz, ${ }^{2}$ \\ Eve Marder ${ }^{1}$ \\ ${ }^{1}$ Volen Center and Biology Department, Brandeis University, Waltham, Massachusetts 02454 \\ ${ }^{2}$ Department of Biological Sciences, Wellesley College, Wellesley, Massachusetts 02481 \\ ${ }^{3}$ Grass Laboratory, Marine Biological Laboratory, Woods Hole, Massachusetts 02543
}

Received 19 June 2002; accepted 17 July 2002

\begin{abstract}
We studied the development of the serotonergic modulation of the stomatogastric nervous system of the lobster, Homarus americanus. Although the stomatogastric ganglion (STG) is present early in embryonic development, serotonin immunoreactivity is not visible in the STG until the second larval stage. However, incubation of the STG with exogenous serotonin showed that a serotonin transporter is present in embryonic and early larval stages. Serotonin uptake was blocked by paroxetine and $0 \% \mathrm{Na}^{+}$saline. The presence of a serotonin transporter in the embryonic STG suggests that hormonally liberated serotonin could be taken up by the STG, and potentially released as a "borrowed transmitter". Consistent with a potential hormonal role, serotonin is found in the pericardial organs, a major neurosecretory structure, by midembryonic development. The rhythmic motor patterns produced by embryonic and larval STGs were decreased in frequency by serotonin.
\end{abstract}

Lateral Pyloric (LP) neuron-evoked excitatory junctional potentials (EJPs) in the embryos and the first larval stage (LI) were larger, slower, and more variable than those in the adult. The amplitude of adult LP neuron-evoked EJPs was increased more than twofold in serotonin, but in embryos and LI preparations this effect was negligible. In embryos and LI preparations, serotonin increased the occurrence of muscle fiber action potentials and altered the EJP wave-form. These data demonstrate that serotonin receptors are present in the stomatogastric nervous system early in development, and suggest that the role of serotonin changes from modulation of muscle fiber excitability early in development to enhancement of neurally evoked EJPs in the adult. ๑) 2002 Wiley Periodicals, Inc. J Neurobiol 54: 380-392, 2003 Keywords: serotonin transporter; "borrowed transmitter"; central pattern generator; neuromodulator; embryonic motor patterns; stomatogastric ganglion; crustaceans; muscle $\mathrm{Ca}^{2+}$ spikes

\section{INTRODUCTION}

Serotonin is an important neuromodulator in lobsters, where it acts both as a circulating hormone and a neu-

*Present address: Department of Neuroscience, Brown University, Providence, RI 02912.

Correspondence to: E. Marder (marder@brandeis.edu).

Contract grant sponsor: National Institutes of Health; contract grant number: NS 17813 (E.M.).

Contract grant sponsor: National Institutes of Health; contract grant number: F31 NS10770 (K.S.R.).

Contract grant sponsor: Grass Foundation Fellowship (K.S.R.).

Contract grant sponsor: NSF; contract grant number: IBN 0091092 (B.S.B.).

Contract grant sponsor: IGERT NSF 450850 Summer Program for Undergraduates (D.J.S.)

(C) 2002 Wiley Periodicals, Inc.

DOI 10.1002/neu.10136 rally released signal to influence a large number of circuits and behaviors (Kravitz et al., 1980; Beltz and Kravitz, 1983; Kravitz, 1988; Edwards and Kravitz, 1997). Additionally, serotonin has pronounced modulatory actions on some crustacean neuromuscular junctions (Dudel, 1965; Glusman and Kravitz, 1982; Dixon and Atwood, 1985; Delaney et al., 1991), including some muscles of the crustacean stomach (Jorge-Rivera et al., 1998). Among the many targets for serotonin is the stomatogastric ganglion (STG) (Beltz et al., 1984; Flamm and Harris-Warrick, 1986a,b; Katz et al., 1989; Kiehn and Harris-Warrick, 1992a,b; Zhang and HarrisWarrick, 1994), where serotonin influences the feeding motor patterns produced by the STG.

We previously showed that serotonin appears relatively late in the development of the STG of the lobster Homarus americanus (Kilman et al., 1999), 
considerably after the time at which the ganglion is first rhythmically active (Casasnovas and Meyrand, 1995; Richards et al., 1999). Specifically, although the STG is rhythmically active by midway through embryonic life (Casasnovas and Meyrand, 1995; Richards et al., 1999), serotonin immunoreactivity in the neuropil of the STG does not strongly appear until the second larval stage (LII) (Kilman et al., 1999), when the animal is already freely feeding (Factor, 1995).

Numerous studies have suggested that, in addition to its actions as a neuromodulator in adult nervous systems, serotonin plays important roles in the development of neuronal circuits. For example, serotonin influences process outgrowth and synapse formation (Haydon et al., 1984; Goldberg and Kater, 1989; Diefenbach et al., 1995; Mercer et al., 1996), and the manipulation of serotonin levels during development alters the structure and function of identified neurons and connections (Mooney et al., 1998; Persico et al., 2000; Sullivan et al., 2000; Benton and Beltz, 2001). This suggests that serotonin might play a developmental role in the stomatogastric nervous system at the time it first appears, around the second larval stage. As a first step in approaching this question, we were curious to determine if serotonin receptors and serotonin transporters are present in the stomatogastric nervous system early in development. In the process of asking these questions we discovered significant developmental alterations in the properties of one of the neuromuscular junctions in the lobster stomach, and in the effects of serotonin on this junction. Specifically, in young animals, serotonin appears to accentuate the intrinsic excitability of the muscle fibers, while in adults there is a strong modulation of the gain of the nerve-muscle synapse.

\section{METHODS}

\section{Animals and Saline}

Adult lobsters, H. americanus, of both sexes were purchased from local fishermen (Commercial Lobster, Boston, MA) and kept in aerated artificial seawater tanks. Embryos and larvae were either obtained from the New England Aquarium and held in artificial seawater tanks at Brandeis University, or obtained from the Massachusetts State Lobster Hatchery and Research Station at Martha's Vineyard and held in chilled running sea water at the Marine Biological Laboratory, Woods Hole. The saline composition (in $\mathrm{m} M$ ) was: $479.12 \mathrm{NaCl}, 12.74 \mathrm{KCl}, 13.67 \mathrm{CaCl}_{2}, 20$ $\mathrm{Mg}_{2} \mathrm{SO}_{4}, 3.91 \mathrm{Na}_{2} \mathrm{SO}_{4}, 5$ HEPES, $\mathrm{pH}=7.4-7.5$.

Embryos were staged according to Helluy and Beltz (1991), and are referred to as their percentage of embryonic development. In the terminology we use in this article, E50 is $50 \%$ of embryonic development. Embryos hatch to become the first larval stage, LI.

\section{Immunocytochemistry}

Embryonic and LI stomachs were dissected in saline according to Kilman et al. (1999). Embryonic ventral nerve cords and pericardial organs (POs) were dissected by making a dorsal incision along the thoracic midline, and pinning down the thoracic body wall alongside the ventral nerve cord. The dissected preparations were incubated for $30 \mathrm{~min}$ to $1 \mathrm{~h}$ in indicated serotonin concentrations, washed thoroughly with saline, then fixed overnight in $4 \%$ paraformaldehyde in $0.1 M$ sodium phosphate buffer, $\mathrm{pH}$ 7.4. They were then washed four to five times in PTA $(0.1 \mathrm{M}$ sodium phosphate buffer, $0.3 \%$ Triton $\mathrm{X}-100$, and $0.1 \% \mathrm{NaN}_{3}, \mathrm{pH}$ 7.4) at approximately $1 \mathrm{~h}$ intervals. The preparations were then incubated overnight in a rat antiserotonin monoclonal antibody (Accurate Chemical and Scientific Corp.) at a final dilution of 1:100 with 10\% goat normal serum (GNS). The next day, the tissues were washed again with PTA four to five times at $1 \mathrm{~h}$ intervals and then incubated in secondary antibody [FITC or Alexafluor 488 (Molecular Probes)] at 1:400 with $10 \%$ GNS. Finally, the preparations were washed as above in $0.1 \mathrm{M}$ sodium phosphate buffer without Triton and mounted in $80 \%$ glycerol and 20\% $0.02 M$ sodium phosphate buffer. Preparations were then imaged with the appropriate filters on either a BioRad MRC-600 or Leica TCS laser scanning confocal microscope. Optical sections were taken approximately every $1-2 \mu \mathrm{m}$ and maximum projections of the $\mathrm{z}$ series were made using Confocal Assistant (BioRad). Photomicrographs were processed in Photoshop 6.0 and Canvas 8.0 before printing on an Epson 1280 printer.

The serotonin uptake inhibitor paroxetine (Smith, Kline, and Beecham) was suspended in normal saline with vigorous shaking and then used immediately. Sodium free saline had the following composition (in $\mathrm{mM}$ ): N-methyl d-Glucamine 479.12, $\mathrm{KCl} 12.74, \mathrm{CaCl}_{2} 13.67, \mathrm{MgSO}_{4} 20, \mathrm{~K}_{2} \mathrm{SO}_{4}$ 3.91, and HEPES 5. For all recipes, the $\mathrm{pH}$ was adjusted to 7.4 using $\mathrm{HCl}$ and $\mathrm{NaOH}$.

\section{Recordings from the Neuromuscular Junctions}

For adult recordings, the stomach was dissected out and the p1 muscle (Maynard and Dando, 1974) was isolated and pinned in a small Sylgard-lined Petri dish (Dow Corning, Midland, MI) along with the lateral ventricular nerve (lvn), which contains the axon of the Lateral Pyloric (LP) neuron that innervates p1 [Fig. 1(B)]. The end of the lvn was surrounded with a Vaseline ${ }^{\mathrm{TM}}$ well and stimulated to produce excitatory junction potentials (EJPs) with bipolar stainless steel pins using an A-M Systems (Carlsborg, WA) isolated pulse stimulator (Model 2100).

For the earlier developmental stages, the entire stomach was dissected from the animal and pinned in the Sylgard dish [Fig. 1(A)]. When necessary, the STG input to the 
muscles was removed by cutting the descending lvn, and a suction electrode was used to stimulate the lvn with a Grass S88 stimulator. Intracellular recordings were then made from muscle bundles that are referred to as lpm (LP-innervated muscle) and lgm [Lateral Gastric (LG) innervated muscle]. We use this nomenclature because the defining boundaries of the adult muscles are not present at this early developmental stage. When these boundaries are defined in the adult, lpm fibers will make up muscles p1 and cpv6, and lgm fibers will become gm6 and gm8 (Maynard and Dando, 1974).

\section{A}

\section{Embryo/LI}

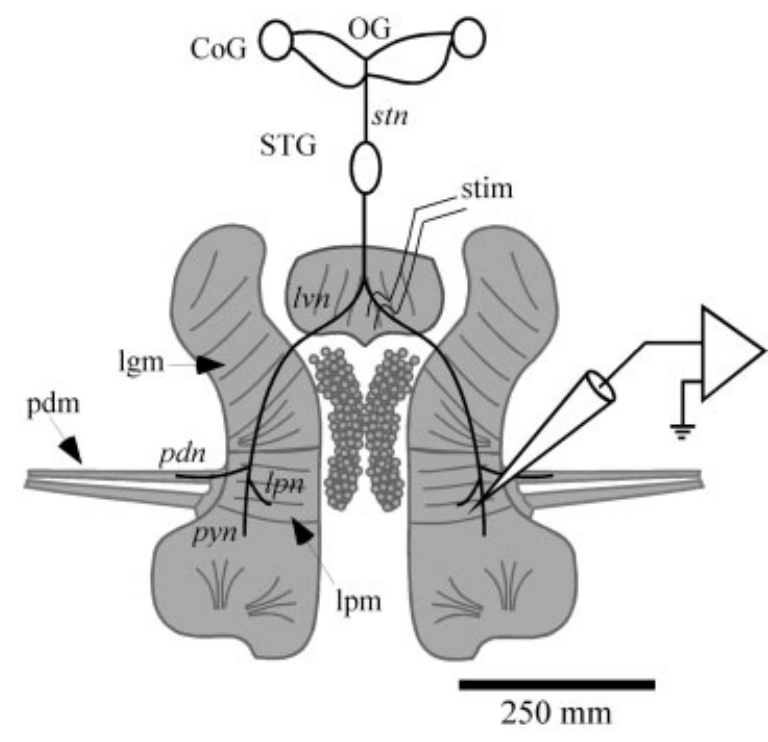

B

\section{Adult}

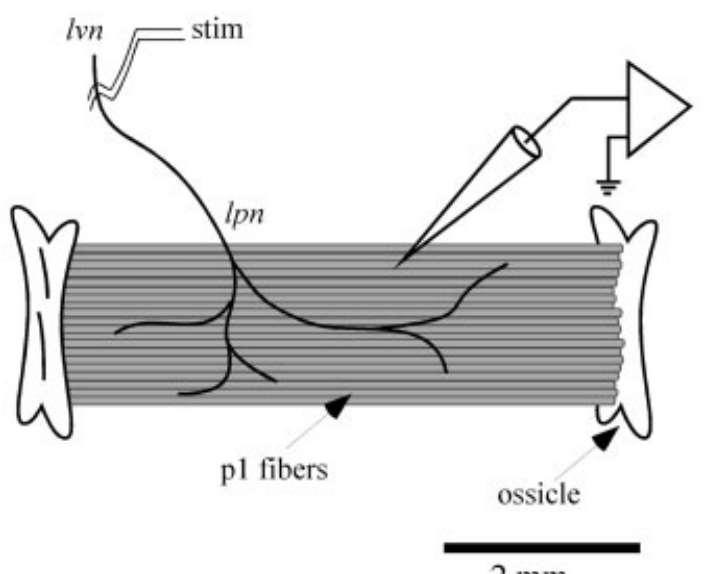

$2 \mathrm{~mm}$
Preparations were continuously superfused with physiological saline at a rate of $8-10 \mathrm{~mL} / \mathrm{min}$, and cooled to $9-13^{\circ} \mathrm{C}$ with a Peltier cooling system. Serotonin (Sigma, St. Louis, MO) was dissolved in saline and added to the superfusion system via a switch at the inflow port. Adult EJPs were recorded in single electrode current clamp with an AxoClamp 2A amplifier and viewed in Clampex 8.1 (Axon Instruments, Foster City, CA). Recording electrodes for adult p1 fibers had resistances of 8-15 $\mathrm{M} \Omega$, filled with 0.6 $M \mathrm{~K}_{2} \mathrm{SO}_{4}$ and $20 \mathrm{mM} \mathrm{KCl}$. Electrodes used in the earlier developmental stages were 50-100 $\mathrm{M} \Omega$ and were filled with $4 M \mathrm{~K}$ acetate and $20 \mathrm{~m} M \mathrm{KCl}$.

Reported EJP amplitudes are the average amplitude of 30 consecutive EJPs stimulated at $1 \mathrm{~Hz}$ (adult) or the first of two paired stimuli at $250 \mathrm{~ms}$ intervals (embryo and LI). The stimulus frequency was chosen to prevent facilitation of the postsynaptic response. The coefficient of variation was computed as the standard deviation of the amplitudes of the 30 events divided by the mean amplitude. The decay time was computed as the time from the peak of the EJP to one-third of the peak amplitude. Quantitative analysis of EJP kinetics was performed with Clampfit 8.1 (Axon Instruments) and statistical analysis was performed with SigmaStat 2.0 (Jandel Scientific Software, San Rafael, CA). Data are reported as means \pm S.E.M (standard error of the mean).

\section{RESULTS}

The lobster, H. americanus, undergoes embryonic development over several months before hatching into its first larval stage (LI). It then molts several times, progressing through larval stages LII and LIII before metamorphosing into the postlarval LIV stage (Factor, 1995). Although the STG is present and active by the midembryonic stage (Casasnovas and Meyrand, 1995), serotonin (5-HT) immunoreactivity in the STG

Figure 1 Schematic diagram of the stomatogastric nervous system and recording configuration for various stages of development. In embryos, larvae, and adults, the paired commissural ganglia (CoGs) and esophageal ganglion (OG) project to the STG via the stomatogastric nerve (stn). Motor neurons in the STG project through the lateral ventricular nerve (lvn) and innervate the stomach muscles. (A) Embryo/LI recording configuration. Intracellular recordings were made from the Lateral Pyloric neuron innervated $\mathrm{p} 1$ muscle (lpm in embryos and larvae). A suction electrode was placed on the lvn to stimulate synaptic events. (B) Adult recording configuration. The $\mathrm{p} 1$ muscle and attached ossicle were dissected free of the stomach and the lvn stimulated with an extracellular electrode. In both (A) and (B), fibers were impaled with glass microelectrodes. 
does not first appear until about the LII stage (Kilman et al., 1999).

\section{5-HT Uptake in Embryos}

Figure 2(A) shows an embryonic STG (E91) labeled with an antibody against 5-HT in control conditions. Note that there is no immunoreactivity present. The preparation in Figure 2(B) was incubated in $10^{-4} \mathrm{M}$ 5-HT for $1 \mathrm{~h}$, washed briefly, and then processed for 5-HT immunoreactivity. Note the dense 5-HT labeling in the processes throughout the neuropil. These processes are derived from the serotonergic GastroPyloric Receptor (GPR) neurons (Katz et al., 1989; Katz and Harris-Warrick, 1989). Figure 3(A) shows 5-HT labeling in the posterior portion of an E91 preparation incubated in $10^{-4} M 5-\mathrm{HT}$ for $30 \mathrm{~min}$. Clearly visible are two groups of GPR cell bodies (asterisks and double asterisks) as well as 5-HT immunoreactive fibers in the lvn and dorsal ventricular nerve (dvn) projecting towards the STG (STG not shown). Figure 3(B) and (C) show single $2 \mu \mathrm{m}$ optical sections of the GPR cell bodies shown in Figure 3(A). 5-HT labeling is present in both the cytoplasm and nuclei of the GPR cell bodies.

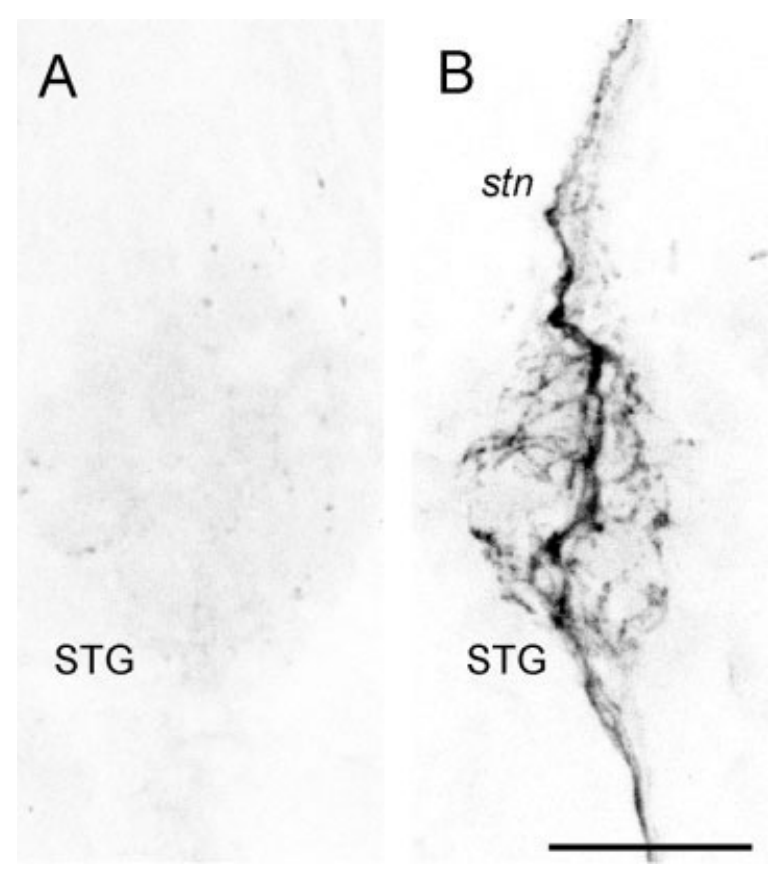

Figure 2 Serotonin uptake in the STG early in development. (A) An unincubated E91 preparation labeled for 5-HT. (B) An E74 STG incubated in $10^{-4} M$ 5-HT for $1 \mathrm{~h}$ at $4{ }^{\circ} \mathrm{C}$ and immunolabeled for 5-HT. Both images are maximum projections of $121.8-\mu \mathrm{m}$ optical sections. Scale bar is $50 \mu \mathrm{m}$ (both panels).

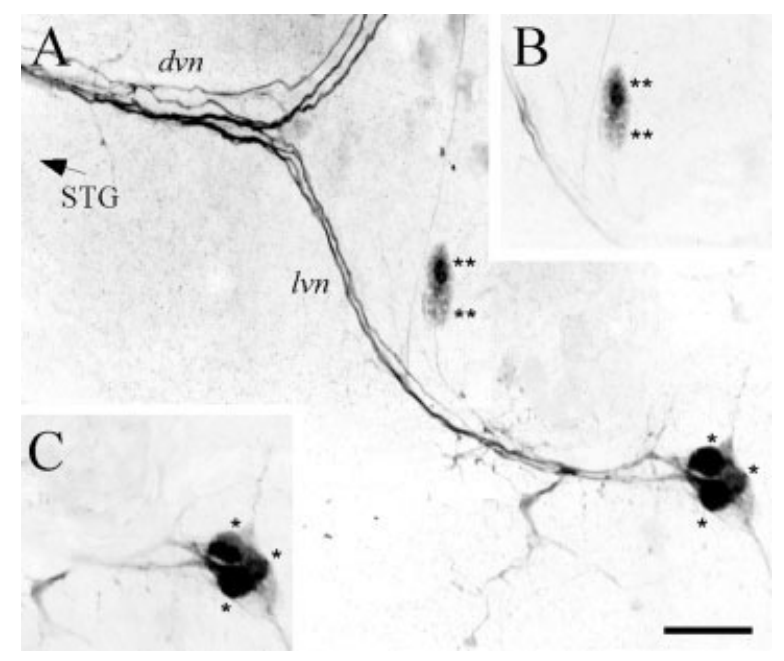

Figure 3 Serotonin uptake in Gastro-Pyloric Receptor (GPR) neurons early in development. (A) An E91 preparation incubated in $10^{-4} M$ 5-HT for $30 \mathrm{~min}$ and immunolabeled for 5-HT. Two groups of GPR neurons (asterisks and double asterisks) send serotonergic projections through the lateral ventricular nerve (lvn) and dorsal ventricular nerve (dvn) towards the STG. The STG is not shown in this preparation. (B) A single $2 \mu \mathrm{m}$ optical section through the anterior-most group of GPR cell bodies. (C) A single $2 \mu \mathrm{m}$ optical section through the posterior (away from STG) group of GPR neurons. Note the presence of 5-HT labeling in the cytoplasm and nuclei of GPR cell bodies. Scale bar is $50 \mu \mathrm{m}$ for all panels.

On the basis of data from 29 embryonic stomach preparations incubated in concentrations of 5-HT from $10^{-4} M$ to $10^{-9} M$, the threshold for significant 5-HT loading into the embryonic STG was between $10^{-8} M$ and $10^{-7} M$, and maximal intensity of staining was seen by about $10^{-5} M$ serotonin. Following uptake of 5-HT by the GPR neurons, an intriguing aspect of the immunocytochemical labeling for 5-HT is the apparent staining of the nuclei of GPR cells [Fig. 3(B,C)].

Paroxetine is a potent inhibitor of 5-HT transport (Bourin et al., 2001). To test the effects of paroxetine on 5-HT transport in the STG, we incubated dissected stomachs with $10^{-4} M$ 5-HT and varying concentrations of paroxetine. Figure 4(A) shows that there was no 5-HT labeling in the STG of an E86 animal treated with $10^{-4}$ $M$ 5-HT and $10^{-4} M$ paroxetine $(n=4)$. When incubated with $10^{-4} M$ 5-HT with $10^{-7} M$ paroxetine [Fig. 4(B); $n=3$ ], faint 5-HT labeling was visible in the STG neuropil. Figure $4(\mathrm{C})$ shows that $10^{-8} M$ paroxetine failed to block uptake of $10^{-4} M$ 5-HT $(n=3)$.

In other systems, 5-HT uptake depends on the presence of extracellular $\mathrm{Na}^{+}$(Humphreys et al., 1994). Figure 4(D) shows an example of an STG from 
an E93 embryo that was incubated in $10^{-4} M$ serotonin in $\mathrm{Na}^{+}$-free saline. Note that the staining in the STG was significantly attenuated. In three out of five preparations the STGs incubated in 5-HT and $\mathrm{Na}^{+}$free saline showed only faint staining in the main process, while the other two preparations showed slight staining in the finer processes as well. All preparations showed attenuated staining when compared with the controls.

\section{Serotonin Staining in Embryonic POs}

The precocious appearance of the 5-HT uptake system suggests the possibility that hormonally liberated

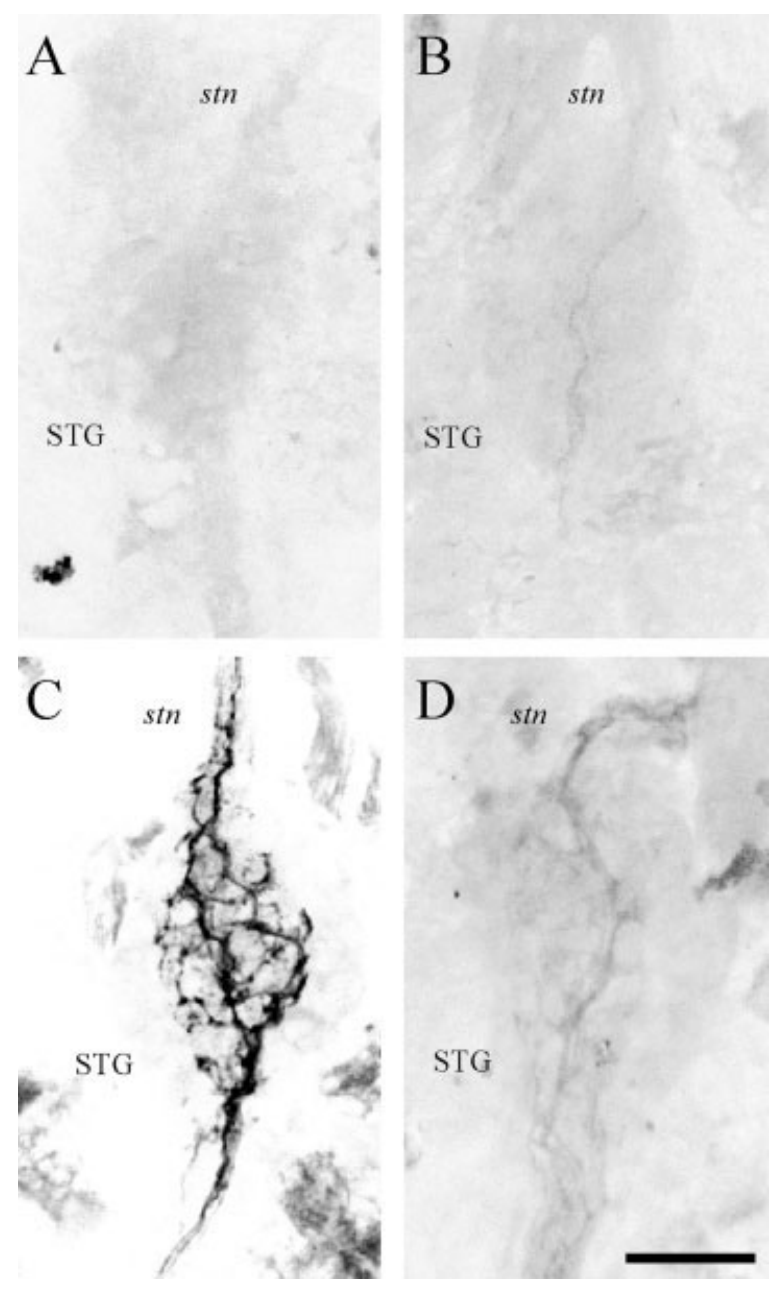

Figure 4 Serotonin uptake is blocked by paroxetine and low sodium. (A) An E86 STG incubated with $10^{-4} M$ 5-HT and $10^{-4} M$ paroxetine. (B) An E80 STG incubated with $10^{-4} M$ 5-HT and $10^{-7} M$ paroxetine. (C) An E83 STG incubated with $10^{-4} M$ 5-HT and $10^{-8} M$ paroxetine. (D) An E93 STG incubated with $10^{-4} M$ serotonin in $0 \%$ sodium saline. All images are maximum projections of $10-131.8-\mu \mathrm{m}$ optical sections. Scale bar is $50 \mu \mathrm{m}$.

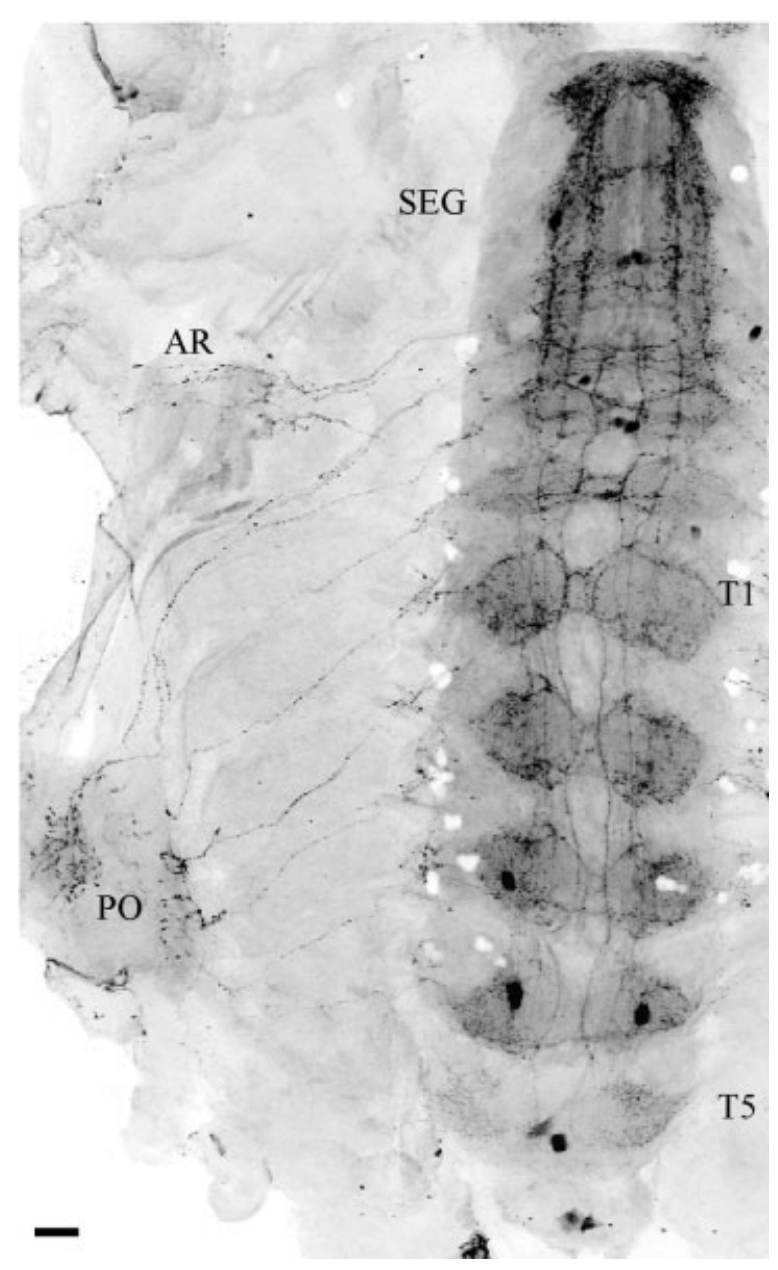

Figure 5 Serotonin in the ventral nerve cord and pericardial organs in an E52 embryo. Fibers project from the SEG and T1-5 to putative hormonal release sites in the POs. Fibers originating in the SEG also ramify in a second neurosecretory region, the AR. Image is a maximum projection of $233-\mu \mathrm{m}$ optical sections. Scale bar is $50 \mu \mathrm{m}$.

5-HT could be taken up by the STG, and possibly used as a "borrowed neurotransmitter", growth factor, or transcriptional regulator (Lebrand et al., 1996, 1998; Cases et al., 1998; Vitalis et al., 1998) early in development. The POs are a major neurosecretory structure that liberates a variety of substances into the hemolymph (Cooke and Sullivan, 1982). Because the STG is in a major artery just anterior to the heart, it is ideally positioned to receive hormones liberated from the POs. The POs in embryos contain 5-HT (Pulver and Marder, 2002).

Figure 5 shows 5-HT labeling in the ventral nerve cord and PO of an E52 animal. Clearly visible are fibers and cell bodies in the subesophageal ganglion (SEG) and thoracic ganglia (T1-5), as previously described (Beltz and Kravitz, 1987; Beltz et al., 1990). Also visible are 
densely labeled varicosities in the PO region as well as less extensive varicosities in the anterior region (AR), another presumed neurosecretory structure. The 5-HT stained segmental nerves that connect the POs to the ventral nerve cord are visible, showing that the 5-HTcontaining PO terminals are derived from ventral nerve cord structures. Similar data were seen in seven complete preparations with the ventral nerve cord attached to the POs. These data show that much of the serotonin neurosecretory system is a potential source of hormonally delivered serotonin to the STG and its musculature in the embryo.

\section{Effects of Serotonin on Embryonic and Larval Motor Patterns}

Serotonin is an important modulator of the STG motor patterns in adult animals (Marder and Eisen, 1984; Flamm and Harris-Warrick, 1986a,b; Katz et al., 1989; Katz and Harris-Warrick, 1989, 1990a,b), including H. americanus (Beltz et al., 1984; Marder and Richards, 1999). The embryonic STG is already rhythmically active by the midembryonic stage (Casasnovas and Meyrand, 1995; Le Feuvre et al., 1999, 2001; Richards et al., 1999; Richards and Marder, 2000), and this activity is similar to that seen in LI animals (Casasnovas and Meyrand, 1995; Richards et al., 1999; Richards and Marder, 2000). Therefore, we were curious to determine if serotonin could influence STG motor patterns in embryos and LI animals, before the STG itself acquires its serotonin.

Figure 6(A) shows dual intracellular recordings from two muscles, the lpm (innervated by the LP motor neuron) and the lgm (innervated by the LG motor neuron) in a LI animal [Fig. 1(A)]. Under control conditions the preparation was rhythmically active, and the discharges recorded in the two muscles occurred almost synchronously. In response to bath application of $10^{-5} M$ 5-HT the burst frequency decreased and the burst duration increased [Fig. 6(B)] These effects were reversible upon washing the preparation in normal saline [Fig. 6(C)]. Pooled data from six LI animals showed a burst frequency of 0.40 $\pm 0.07 \mathrm{~Hz}$ in control saline and $0.18 \pm 0.09 \mathrm{~Hz}$ in 5-HT (paired $t$ test, $p<.002$ ). Similar data were obtained from nine embryonic preparations in which the control frequency decreased from a mean of 0.33 $\pm 0.04 \mathrm{~Hz}$ to $0.17 \pm 0.04 \mathrm{~Hz}$ in $5-\mathrm{HT}(p<.01)$.

In the process of studying the effects of serotonin on the motor patterns in the embryos we noticed that in some preparations serotonin had a marked effect on the duration and shape of the EJPs. The top panel of Figure 7 shows a recording from a lpm in an E91 preparation. The bottom trace shows the preparation in the presence of $10^{-5} M$ 5-HT. Note that in 5-HT some of the depolarizations are broader, and it appears that single EJPs are triggering action potentials (asterisks). These regenerative events are more common in the presence of 5-HT than in control conditions (top panel, single asterisk).

Of the experiments included in this study, four of nine embryonic preparations and three of six larval preparations had these altered events when serotonin was applied to spontaneously active preparations driven by the STG. These data suggested the possibility that serotonin could be acting directly on the muscle membrane, and made it important to study nerve-evoked EJPs under more controlled conditions to determine if serotonin was having direct actions at the neuromuscular junction.

\section{Developmental Regulation of LP-Evoked EJPs in Control Saline}

In this section we first compare nerve-evoked EJPs in embryos, LI, and adult muscles. In the analysis of EJP properties described below, only preparations that did not show either spontaneous action potentials or serotonin-evoked action potentials were used. This was done to study separately the properties of the EJPs and the action potentials. Thus, we have excluded for this analysis those preparations in which the amplitude and time course of EJPs were likely to be "contaminated" by muscle fiber regenerative currents. The criteria for inclusion in this data set was that successive EJPs had to be essentially identical in time course and wave-form.

In these experiments the STG was removed and the lvn was stimulated. Figure 8(A) shows overlays of the averages of 30 consecutive EJPs recorded at each time period. Note that the amplitude in the adult is considerably smaller than what is seen in the embryo and LI. The EJP amplitude increased slightly from $12.9 \pm 3.9$ $\mathrm{mV}$ in embryos to $17.9 \pm 2.8 \mathrm{mV}$ in larvae. However, in adults, EJP amplitude decreased significantly from both embryonic and larval values to $3.3 \pm 0.5 \mathrm{mV}$ (one-way ANOVA on ranks, $p<.05, n=8$ for embryos, $n=10$ for larvae, $n=15$ for adults).

Figure 8(B) shows a comparison of the EJP decay at the three time periods. When the EJPs are scaled to the same amplitude, changes in decay times are readily seen. Figure 8(B) shows that the time to decay for adults was faster than for the embryos and larvae. Times to onethird amplitude for EJPs were $95 \pm 24 \mathrm{~ms}$ in embryos, $98 \pm 16 \mathrm{~ms}$ in larvae, and $37 \pm 3 \mathrm{~ms}$ in adults. The decay times are highly variable, but the decrease in decay time from both embryos and larvae to adults is significant (one-way ANOVA, $p<.05, n=8$ for embryos, $n=10$ for larvae, $n=15$ for adults). 

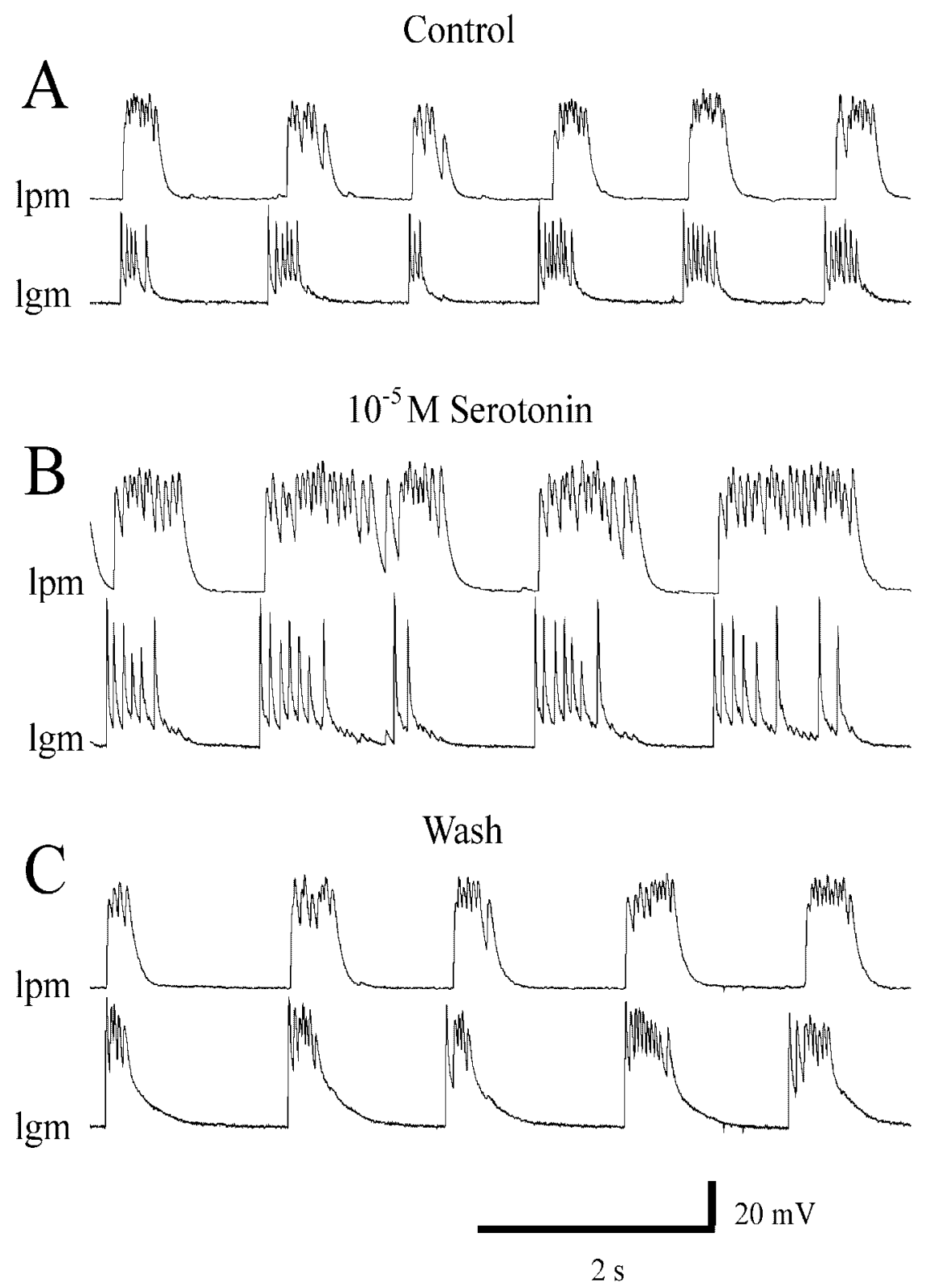

Figure 6 The effects of serotonin on the STG motor pattern early in development. Paired recordings of pyloric (lpm, top) and gastric (lgm, bottom) muscles in a LI animal. (A) Control saline. Resting potentials: $-80 \mathrm{mV}$ (lpm), $-80 \mathrm{mV}$ (lgm). (B) $10^{-5} M$ 5-HT. Resting potentials: $-87 \mathrm{mV}$ (lpm), $-80 \mathrm{mV}$ (lgm). (C) Wash. Resting potentials: $-80 \mathrm{mV}$ (lpm), $-60 \mathrm{mV}$ (lgm).

Figure $8(\mathrm{C})$ compares the variability in the release of neurotransmitter at the three developmental time periods. In each preparation we recorded 30 consecutive EJPs stimulated at $1 \mathrm{~Hz}$, and computed the coefficient of variation (CV) of the 30 EJP amplitudes. Figure 8(C) shows 10 consecutive EJPs overlaid in embryos, larvae, and adult to demonstrate the variability in amplitude. The CV of embryonic EJPs was $0.227 \pm 0.038$ while the $C V$ in larvae was 0.311 \pm 0.045 and the $\mathrm{CV}$ in adults was $0.135 \pm 0.015$. The decrease in $\mathrm{CV}$ from embryos and larvae to adults was significant (one-way ANOVA, $p<.05, n=8$ for embryos, $n=10$ for larvae, $n=15$ for adults).

\section{Age-Dependent Effects of Serotonin on EJPs}

Figure 9 compares the effects of $10^{-5} M$ 5-HT on EJP amplitude, time to decay, and CV in embryos, LIs, 
Control

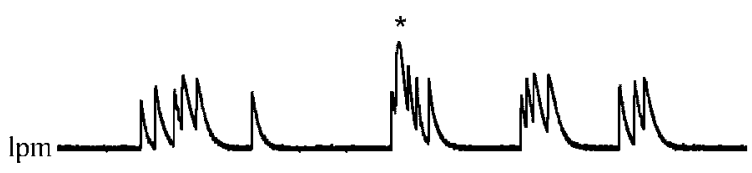

$10^{-5} \mathrm{M}$ Serotonin

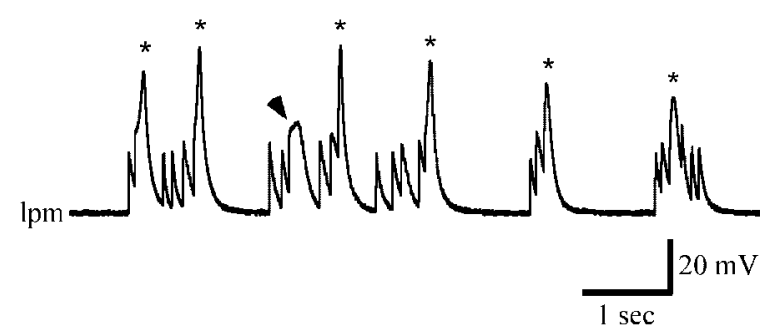

Figure 7 Bath application of serotonin can change the shape of EJPs in rhythmically active preparations. Intracellular recordings from $\mathrm{lpm}$ in an E84 animal. Top trace, control saline; bottom trace, $10^{-5} M$ 5-HT. Asterisks indicate onset of action potentials triggered by single EJPs. Note that one widened depolarization in 5-HT fails to trigger a muscle action potential (arrow). Resting potentials: -64 $\mathrm{mV}$ (control), $-58 \mathrm{mV}$ (5-HT). and adults. Figure $9(\mathrm{~A}, \mathrm{~B})$ shows that there was no significant difference in EJP amplitude in embryos (control: $13.3 \pm 4.4 \mathrm{mV}, 5$-HT: $14.0 \pm 5.1 \mathrm{mV}, p$ $=.554$, paired $t$ test, $n=7$ ) and larvae (control: 20.2 $\pm 2.7 \mathrm{mV}, 5$-HT: $24.5 \pm 3.1 \mathrm{mV}, p=.108$, paired $t$ test, $n=6$ ), but EJP amplitude in adults increased significantly from $3.9 \pm 0.8 \mathrm{mV}$ in control to 9.6 $\pm 1.9 \mathrm{mV}$ in 5-HT ( $p=.006$, paired $t$ test, $n=7)$.

Consistent with its failure to increase EJP amplitude in embryos and larvae, 5-HT did not significantly decrease the CV of EJP amplitude, as seen in Figure 8(B) (embryo: control, $0.215 \pm 0.042,5$-HT, 0.208 $\pm 0.035, p=.781$, paired $t$ test, $n=7$; larvae: control, $0.292 \pm 0.056,5-\mathrm{HT}, 0.180 \pm 0.032, p$ $=.132$, paired $t$ test, $n=6$ ). In adults, the CV significantly decreased in the presence of serotonin, indicative of an enhancement of transmitter release (from $0.122 \pm 0.027$ in control saline to 0.076 $\pm 0.017, p=.034$ in 5-HT, paired $t$ test, $n=7$ ).

Serotonin did not significantly affect the decay time in embryos (control, $81 \pm 23 \mathrm{~ms}, 5-\mathrm{HT}, 182$ $\pm 40 \mathrm{~ms}, p=.064$, paired $t$ test, $n=7$ ), larvae (control, $82 \pm 17 \mathrm{~ms}$ to $134 \pm 51 \mathrm{~ms}, p=.315$, paired $t$ test, $n=5$ ), or adults (from $35 \pm 3$ to $30 \pm 3$ $\mathrm{ms}, p=.241$, paired $t$ test, $n=7$ ). Although there are no statistically significant differences between the
A
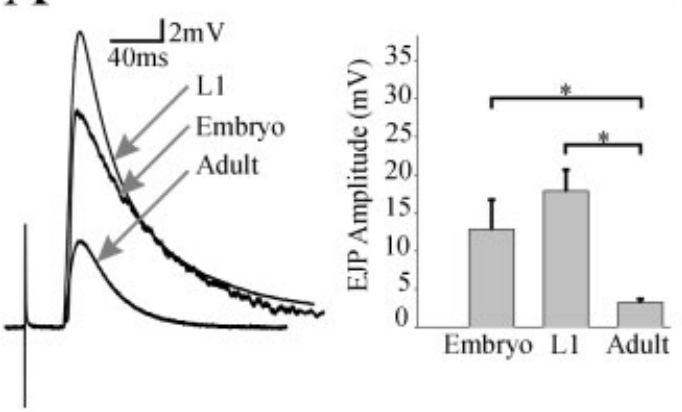

C

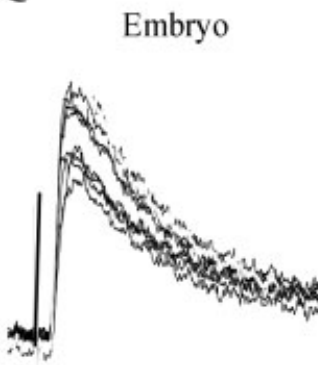

L1

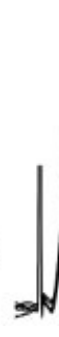

B
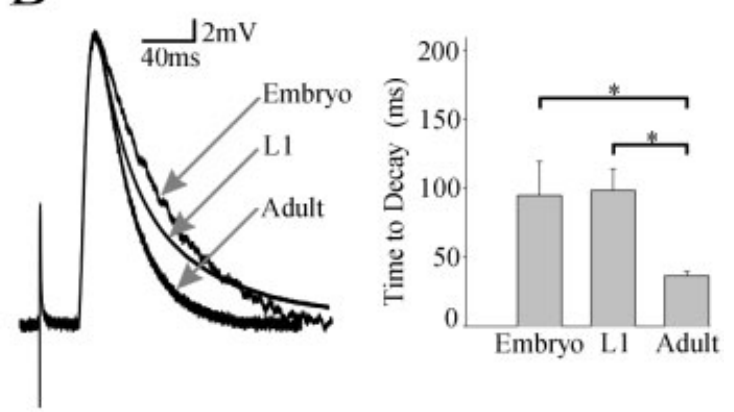

Adult

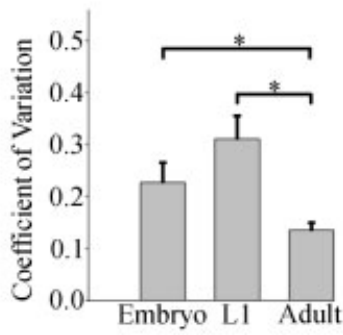

Figure 8 Comparison of evoked EJPs in embryos, LIs, and adults. All recordings are from the $\mathrm{lpm} / \mathrm{p} 1$ muscle. (A) Overlaid averages of 30 consecutive EJPs evoked at $1 \mathrm{~Hz}$ in an embryo, LI, and adult. (B) Average of 30 consecutive EJPs in an embryo, LI, and adult scaled to the same amplitude. (C) Thirty consecutive EJPs overlaid to show variability in amplitude. 
control and serotonin data, serotonin tended to increase the duration of the EJP in embryos and larvae and decrease the duration in adults. Note that these data come from preparations showing no spontaneous or serotonin-induced action potentials. Serotonin did not alter the amplitude of responses to iontophoretically applied glutamate in the adult $(n=4)$.

\section{Serotonin and Muscle Action Potentials}

Spontaneous muscle action potentials were never seen in the adult muscle preparations. However, spontaneous muscle action potentials were sometimes seen in embryonic and larval preparations, and serotonin increased the likelihood that EJPs would trigger muscle spikes. Figure 10 shows recordings from a LI preparation in which nerve-evoked EJPs sometimes triggered muscle action potentials in control saline. The top panel shows recordings of 35 responses triggered on the stimulus. Most of the EJPs failed to trigger a muscle action potential, but seven of the EJPs were followed by a muscle action potential, with a variable latency after the stimulus. The bottom trace of Figure 10 shows the same preparation in the presence of $10^{-5} M$ 5-HT. Note that all of the EJPs triggered

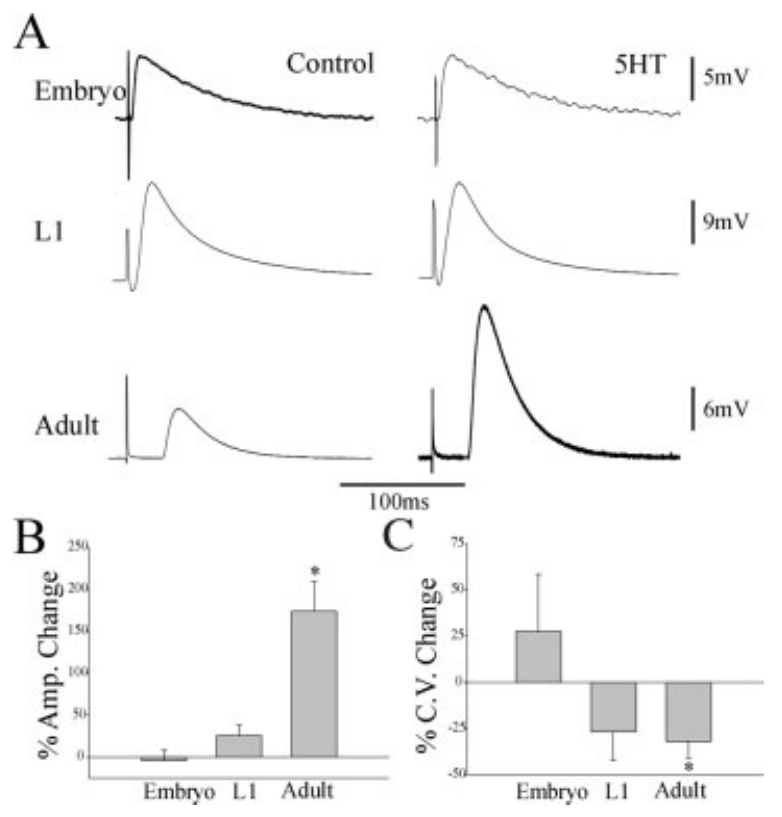

Figure 9 The effects of serotonin on evoked EJPs in lpm/p1 muscles. (A) An average of 30 consecutive EJPs in embryos (top trace), LIs (middle trace), and adults (bottom trace) in both control saline (left column) and after $\approx 10 \mathrm{~min}$ in $10^{-5} M$ 5-HT (right column). (B) The effect of 5-HT EJP amplitude in embryos, larvae, and adults. (C) CV on 30 consecutive evoked EJPs in adults, embryos, and larvae in control saline and in 5-HT.

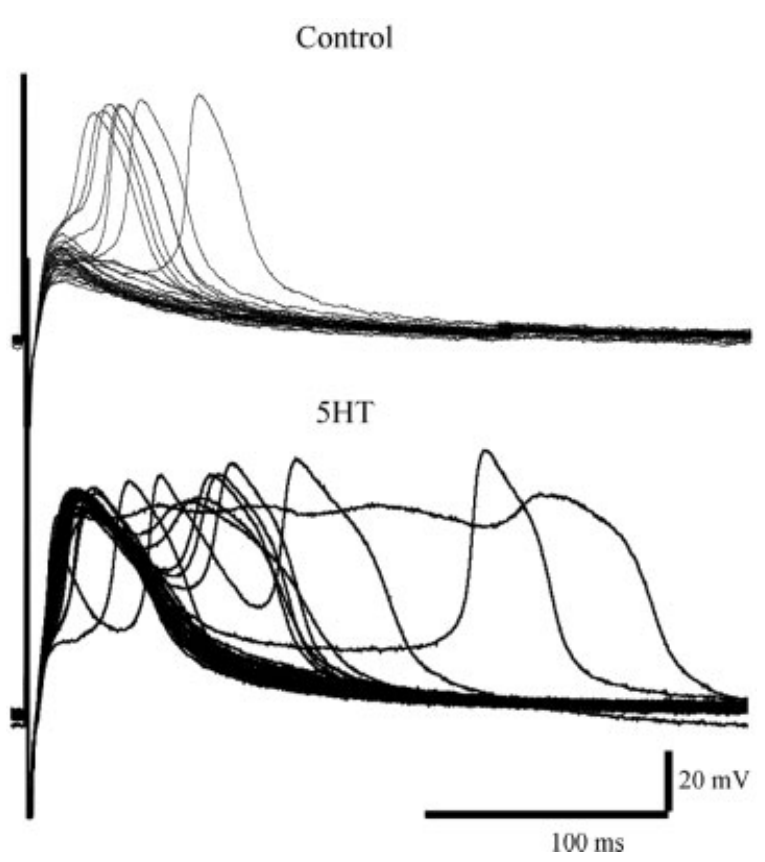

Figure 10 Stimulus triggered action potentials were altered by serotonin bath application. Evoked EJPs in a LI lpm (30 sweeps/trace). Top trace, control saline; bottom trace, $10^{-5} M$ 5-HT.

spikes, most of them immediately on the rising phase of the EJP, but others at a longer latency. Also note that the triggered action potentials were wider than in control, and that several stimuli elicited two spikes. The spike width measured at $20 \mathrm{mV}$ went from an average of $20 \pm 6 \mathrm{~ms}$ in control to $40 \pm 4 \mathrm{~ms}$ in serotonin $(p=.022)$. Similar data were obtained in three preparations.

\section{DISCUSSION}

In the stomatogastric nervous system of the lobster, $H$. americanus, serotonin is found in the peripherally located GPR neurons that project into the neuropil of the STG and from there to more anterior ganglia (Beltz et al., 1984; Katz et al., 1989; Katz and HarrisWarrick, 1989). In a previous study we found that serotonin does not first appear in the stomatogastric nervous system until about LII, the second larval stage of development (Kilman et al., 1999). The late appearance of serotonin in the stomatogastric nervous system suggested that it might play an important developmental role in the maturation of the circuitry and motor patterns of the STG. This may, in fact, still be true, but the data in this article suggest that hormonally released serotonin could be acting physiolog- 
ically much earlier in development, both on the STG itself, and on the stomach neuromuscular junctions.

The POs are a major source of neurohormones for crustaceans (Cooke and Sullivan, 1982; Keller, 1992). The POs acquire a large number of their neuromodulators, including serotonin (Fig. 5), early in embryonic development (Pulver and Marder, 2002). Hormones released from the POs will be rapidly delivered both to the STG itself and to the stomach musculature, which is bathed in hemolymph. Interestingly, in this article we demonstrate that the STG itself, as well as one of the neuromuscular junctions, might be early sites of action of hormonally delivered serotonin.

\section{What Role Does Serotonin Play in the Embryonic STG?}

We have shown that a serotonin transporter is present in embryos and LI animals (Figs. 2 and 3), and that the nuclei as well as cytoplasm of the GPR cells (Fig. 3) apparently become immunoreactive following serotonin uptake. This raises the possibility that serotonin acts as a borrowed transmitter and/or as an intracellular regulator at these early stages. The concept of serotonin acting as a borrowed transmitter suggests that the GPR cells take up and concentrate serotonin, possibly to release it at a later time. In this way hormonally liberated serotonin could temporarily alter the cotransmitter phenotype of the embryonic GPR neurons. Alternatively, or in addition to this function, serotonin may act intracellularly as a growth or transcriptional regulator within the GPR cells. The apparent staining of the GPR nuclei [Fig. 3(B,C)] suggests that after uptake serotonin may, indeed, be transported retrogradely to the nucleus.

There are precedents for these nontraditional actions of serotonin in both invertebrates and vertebrates. In the mouse brain, the serotonin transporter is expressed widely at embryonic stages before synapses have formed (Bruning et al., 1997). Thalamocortical relay neurons do not synthesize serotonin, but become immunoreactive for it as a result of taking up extracellular serotonin, probably released by Raphe neurons (Lebrand et al., 1996). The thalamocortical neurons also express the vesicular monoamine transporter, and are responsible for a transient serotoninergic innervation of cortex thought to be developmentally important. Thus, it is unclear whether these relay neurons use serotonin as a growth regulatory molecule, as a transient borrowed transmitter, or both. Likewise, in the lobster brain, newborn olfactory interneurons show a transient uptake of serotonin within a few hours of their birth (Beltz et al., 2001). These neurons never show serotonin immunoreactiv- ity later in life, and therefore are not believed to contain the synthetic enzymes for serotonin. In these neurons, it has been proposed that serotonin uptake may be associated with survival and/or branching of the newborn neurons via an intracellular regulatory action (Beltz et al., 2001), as serotonin levels are known to influence these aspects of neuronal development in lobsters (Sullivan et al., 2000; Beltz et al., 2001; Benton and Beltz, 2001).

In the STG, functions of serotonin as a borrowed transmitter or intracellular regulator are both possible. Although we have not directly demonstrated that the serotonin that accumulates as a result of the action of the transporter is releasable, there is no reason to suspect that it may not be. Released serotonin could alter the physiology or developmental progress of targets in the STG. As our data also demonstrate that the embryonic STG already responds to serotonin, "borrowed" serotonin may modulate the embryonic STG motor patterns before the animal is freely eating (LI), but while the STG circuits are being tuned during development. On the other hand, the possible action of serotonin as an intracellular regulator in the GPR neurons suggests a direct role in the morphogenesis of these cells. Serotonin has been implicated as an intracellular signaling molecule or transcriptional regulator in a variety of other systems (Lebrand et al., 1996; Liu et al., 1997; Torres et al., 1998; Laflamme et al., 1999), although the specific actions of serotonin are a topic of speculation. The role that serotonin may play as an intracellular regulator during the development of the GPR neurons will require further investigation of this phenomenon.

\section{Developmental Regulation of the Action of Serotonin on the p1 Neuromuscular Junction}

Although some adult crustacean muscles display $\mathrm{Ca}^{2+}$ spikes either spontaneously or in response to neuromodulator application (Kravitz et al., 1980; Lingle, 1981), we have not seen spikes or any obvious regenerative activity in the adult $\mathrm{p} 1$ muscle, either in control saline or in the presence of serotonin. In contrast, in embryonic and larval muscles, muscle action potentials were sometimes seen in some control preparations, and were more often seen in response to serotonin. Muscle action potentials were often initiated at the peak of nerve-evoked depolarizations in embryonic and larval p1 fibers, as if the EJPs were bringing the muscle fiber to threshold for the spike. This strongly suggests that there is a postsynaptic action of serotonin in the young animals. Despite the fact that serotonin enhanced the amplitude of the adult 
EJPs to the range of the embryonic EJPs, these larger EJPs did not evoke action potentials, nor did depolarization with intracellular microelectrodes. Obviously, it is possible that the adult muscle fibers may still be able to fire action potentials under some modulatory conditions, but it appears that they are largely without this function in control saline or serotonin.

In other crustacean preparations, muscle action potentials are $\mathrm{Ca}^{2+}$ mediated. In many developing systems, early $\mathrm{Ca}^{2+}$ spikes are thought to be important for setting the stage for the development of excitability and synaptic structure (Spitzer, 1994; Moody, 1998a,b; Spitzer and Ribera, 1998). Similarly, here it is possible that when the EJPs trigger a spike, the increase in $\mathrm{Ca}^{2+}$ concentration is used to stabilize developing neuromuscular junctions.

As at other crustacean neuromuscular junction systems (Dudel, 1965; Glusman and Kravitz, 1982; Dixon and Atwood, 1985; Delaney et al., 1991), the serotonin-mediated enhancement of transmitter release at the adult LP-p1 neuromuscular synapse is seen as an increase in EJP amplitude and a corresponding decrease in the variability of the EJPs. The decrease in the CV of the EJPs is consistent with a presynaptic action of serotonin, and this is consistent with the finding that serotonin has no effect on the amplitude of the response to iontophoretically applied glutamate (data not shown). Because serotonin is known to activate multiple receptors and multiple signal transduction pathways in crustacean nerve muscle preparations (Dixon and Atwood, 1989a,b,c; Goy and Kravitz, 1989), it is possible that there is a developmental switch in the extent to which these multiple serotonin-activated pathways are expressed. Thus, our data are consistent with a predominantly postsynaptic action of serotonin on muscle excitability in the young animals, and a predominantly presynaptic action of serotonin on transmitter release in the adult.

\section{CONCLUSIONS}

Serotonin has physiological actions in both embryonic and adult stomatogastric preparations, but there appears to be a complex suite of developmental changes in serotonin's actions over development. All neurally released serotonin in the adult is thought to derive from the GPR terminals (Katz et al., 1989; Katz and Harris-Warrick, 1989). The GPR neurons are stretch receptors and contain several cotransmitters, which in H. americanus include acetylcholine, serotonin, FLRFamide-like peptides, and allatostatin-like peptides (Kilman et al., 1999). In the crab, C. borealis, the
GPR neurons produce both rapid cholinergic actions and slower modulatory actions that have been attributed to serotonin (Katz et al., 1989; Katz and HarrisWarrick, 1989, 1990a,b, 1991). We know that the GPR neurons are present early in development because they stain with their other cotransmitters (Kilman et al., 1999) and take-up serotonin. Nonetheless, if they are active early in development this means that they will function with their other cotransmitters, but not with serotonin unless hormonally released serotonin loads the GPR neurons sufficiently to allow them to release serotonin. This suggests that the cotransmitter complement of the GPR neurons early in development may be hormonally regulated, or hormonally gated, via the ability of the GPR neurons to take up serotonin. At present, we do not know the physiological circumstances under which the embryonic POs are likely to release serotonin, so we have no way of knowing whether the GPR neurons are likely to load and possibly release serotonin often or rarely.

Serotonin is active on the LP to p1 neuromuscular junction in both embryos and adults, but these actions change over development, as do the properties of the neuromuscular junctions themselves. Early in development the neurally evoked EJPs are large and variable, and serotonin appears to increase the likelihood that muscle action potentials or prolonged EJPs will be seen. In adults, the neurally evoked EJPs are smaller and more constant, and the effect of serotonin appears to predominantly regulate the amplitude of the EJP, but not muscle fiber membrane excitability. Together, all of the data in this article demonstrate that serotonin elicits a complex suite of actions during development and adult life. The dual roles of serotonin as a rapid modulator and a developmental regulator are inextricably intertwined, as together these mechanisms shape the motor patterns produced throughout the lifetime of the animal.

We thank Dr. Michael Tlusty of the New England Aquarium and Dr. Michael Syslo of the Massachusetts State Lobster Hatchery and Research Station in Martha's Vineyard for supplying animals. We thank Smith, Kline, and Beecham for the gift of paroxetine.

\section{REFERENCES}

Beltz B, Eisen JS, Flamm R, Harris-Warrick RM, Hooper S, Marder E. 1984. Serotonergic innervation and modulation of the stomatogastric ganglion of three decapod crustaceans (Panulirus interruptus, Homarus americanus and Cancer irroratus). J Exp Biol 109:35-54.

Beltz BS, Benton JL, Sullivan JM. 2001. Transient uptake 
of serotonin by newborn olfactory projection neurons. Proc Natl Acad Sci USA 98:12730-12735.

Beltz BS, Kravitz EA. 1983. Mapping of serotonin-like immunoreactivity in the lobster nervous system. J Neurosci 3:585-602.

Beltz BS, Kravitz EA. 1987. Physiological identification, morphological analysis, and development of identified serotonin-proctolin containing neurons in the lobster ventral nerve cord. J Neurosci 7:533-546.

Beltz BS, Pontes M, Helluy S, Kravitz E. 1990. Patterns of appearance of serotonin and proctolin immunoreactivities in the nervous system of the lobster. J Neurobiol 21:521542.

Benton J, Beltz B. 2001. Effects of serotonin depletion on local interneurons in the developing olfactory pathway of lobsters. J Neurobiol 46:193-205.

Bourin M, Chue P, Guillon Y. 2001. Paroxetine: a review. CNS Drug Rev 7:25-47.

Bruning G, Liangos O, Baumgarten HG. 1997. Prenatal development of the serotonin transporter in mouse brain. Cell Tissue Res 289:211-221.

Casasnovas B, Meyrand P. 1995. Functional differentiation of adult neural circuits from a single embryonic network. J Neurosci 15:5703-5718.

Cases O, Lebrand C, Giros B, Vitalis T, De Maeyer E, Caron MG, Price DJ, Gaspar P, Seif I. 1998. Plasma membrane transporters of serotonin, dopamine, and norepinephrine mediate serotonin accumulation in atypical locations in the developing brain of monoamine oxidase A knock-outs. J Neurosci 18:6914-6927.

Cooke IM, Sullivan RE. 1982. Hormones and neurosecretion. In: Atwood HL, Sandeman DC, editors. The Biology of Crustacea: Neurobiology. New York: Academic Press, p 205-290.

Delaney K, Tank DW, Zucker RS. 1991. Presynaptic calcium and serotonin-mediated enhancement of transmitter release at crayfish neuromuscular junction. J Neurosci 11:2631-2643.

Diefenbach TJ, Sloley BD, Goldberg JI. 1995. Neurite branch development of an identified serotonergic neuron from embryonic Helisoma: evidence for autoregulation by serotonin. Dev Biol 167:282-293.

Dixon D, Atwood HL. 1985. Crayfish motor nerve terminal's response to serotonin examined by intracellular microelectrode. J Neurobiol 16:409-424.

Dixon D, Atwood HL. 1989a. Adenylate cyclase system is essential for long-term facilitation at the crayfish neuromuscular junction. J Neurosci 9:4246-4252.

Dixon D, Atwood HL. 1989b. Conjoint action of phosphatidylinositol and adenylate cyclase systems in serotonininduced facilitation at the crayfish neuromuscular junction. J Neurophysiol 62:1251-1259.

Dixon D, Atwood HL. 1989c. Phosphatidylinositol system's role in serotonin-induced facilitation at the crayfish neuromuscular junction. J Neurophysiol 62:239-246.

Dudel J. 1965. Facilitatory effects of 5-hydroxy-tryptamine on the crayfish neuromuscular junction. Arch exp Path u Pharmak 249:515-528.
Edwards DH, Kravitz EA. 1997. Serotonin, social status and aggression. Curr Opin Neurobiol 7:812-819.

Factor JR, editor. 1995. Biology of the Lobster, Homarus americanus. San Diego: Academic Press. 528 p.

Flamm RE, Harris-Warrick RM. 1986a. Aminergic modulation in lobster stomatogastric ganglion. I. Effects on motor pattern and activity of neurons within the pyloric circuit. J Neurophysiol 55:847-865.

Flamm RE, Harris-Warrick RM. 1986b. Aminergic modulation in lobster stomatogastric ganglion. II. Target neurons of dopamine, octopamine, and serotonin within the pyloric circuit. J Neurophysiol 55:866-881.

Glusman S, Kravitz EA. 1982. The action of serotonin on excitatory nerve terminals in lobster nerve-muscle preparations. J Physiol 325:223-241.

Goldberg JI, Kater SB. 1989. Expression and function of the neurotransmitter serotonin during development of the $\mathrm{He}$ lisoma nervous system. Dev Biol 131:483-495.

Goy MF, Kravitz EA. 1989. Cyclic AMP only partially mediates the actions of serotonin at lobster neuromuscular junctions. J Neurosci 9:369-379.

Haydon PG, McCobb DP, Kater SB. 1984. Serotonin selectively inhibits growth cone motility and synaptogenesis of specific identified neurons. Science 226:561-564.

Helluy SM, Beltz BS. 1991. Embryonic development of the American lobster: quantitative staging and characterization of an embryonic molt cycle. Biol Bull 180:355-371.

Humphreys CJ, Wall SC, Rudnick G. 1994. Ligand binding to the serotonin transporter: equilibria, kinetics, and ion dependence. Biochemistry 33:9118-9125.

Jorge-Rivera JC, Sen K, Birmingham JT, Abbott LF, Marder E. 1998. Temporal dynamics of convergent modulation at a crustacean neuromuscular junction. J Neurophysiol 80:2559-2570.

Katz PS, Eigg MH, Harris-Warrick RM. 1989. Serotonergic/cholinergic muscle receptor cells in the crab stomatogastric nervous system. I. Identification and characterization of the gastropyloric receptor cells. J Neurophysiol 62:558-570.

Katz PS, Harris-Warrick RM. 1989. Serotonergic/cholinergic muscle receptor cells in the crab stomatogastric nervous system. II. Rapid nicotinic and prolonged modulatory effects on neurons in the stomatogastric ganglion. J Neurophysiol 62:571-581.

Katz PS, Harris-Warrick RM. 1990a. Actions of identified neuromodulatory neurons in a simple motor system. Trends Neurosci 13:367-373.

Katz PS, Harris-Warrick RM. 1990b. Neuromodulation of the crab pyloric central pattern generator by serotonergic/ cholinergic proprioceptive afferents. J Neurosci 10:14951512.

Katz PS, Harris-Warrick RM. 1991. Recruitment of crab gastric mill neurons into the pyloric motor pattern by mechanosensory afferent stimulation. J Neurophysiol 65 : 1442-1451.

Keller R. 1992. Crustacean neuropeptides: structures, functions and comparative aspects. Experientia 48:439-448.

Kiehn O, Harris-Warrick RM. 1992a. 5-HT modulation of 
hyperpolarization-activated inward current and calciumdependent outward current in a crustacean motor neuron. J Neurophysiol 68:496-508.

Kiehn O, Harris-Warrick RM. 1992b. Serotonergic stretch receptors induce plateau properties in a crustacean motor neuron by a dual-conductance mechanism. J Neurophysiol 68:485-495.

Kilman VL, Fénelon V, Richards KS, Thirumalai V, Meyrand P, Marder E. 1999. Sequential developmental acquisition of cotransmitters in identified sensory neurons of the stomatogastric nervous system of the lobsters, Homarus americanus and Homarus gammarus. J Comp Neurol 408:318-334.

Kravitz EA. 1988. Hormonal control of behavior: amines and the biasing of behavioral output in lobsters. Science 241:1775-1781.

Kravitz EA, Glusman S, Harris-Warrick RM, Livingstone MS, Schwarz T, Goy MF. 1980. Amines and a peptide as neurohormones in lobsters: actions on neuromuscular preparations and preliminary behavioural studies. J Exp Biol 89:159-175.

Laflamme N, Feuvrier E, Richard D, Rivest S. 1999. Involvement of serotonergic pathways in mediating the neuronal activity and genetic transcription of neuroendocrine corticotropin-releasing factor in the brain of systemically endotoxin-challenged rats. Neuroscience 88:223-240.

Lebrand C, Cases O, Adelbrecht C, Doye A, Alvarez C, El Mestikawy S, Seif I, Gaspar P. 1996. Transient uptake and storage of serotonin in developing thalamic neurons. Neuron 17:823-835.

Lebrand C, Cases O, Wehrle R, Blakely RD, Edwards RH, Gaspar P. 1998. Transient developmental expression of monoamine transporters in the rodent forebrain. J Comp Neurol 401:506-524.

Le Feuvre Y, Fénelon VS, Meyrand P. 1999. Unmasking of multiple adult neural networks from a single embryonic circuit by removal of neuromodulatory inputs. Nature 402:660-664.

Le Feuvre Y, Fénelon VS, Meyrand P. 2001. Ontogeny of modulatory inputs to motor networks: early established projection and progressive neurotransmitter acquisition. J Neurosci 21:1313-1326.

Lingle C. 1981. The modulatory action of dopamine on crustacean foregut neuromuscular preparations. J Exp Biol 94:285-299.

Liu QR, Hattar S, Endo S, MacPhee K, Zhang H, Cleary LJ, Byrne JH, Eskin A. 1997. A developmental gene (Tolloid/BMP-1) is regulated in Aplysia neurons by treatments that induce long-term sensitization. J Neurosci 17:755-764.

Marder E, Eisen JS. 1984. Electrically coupled pacemaker neurons respond differently to the same physiological inputs and neurotransmitters. J Neurophysiol 51:1362-1374.

Marder E, Richards KS. 1999. Development of the peptidergic modulation of a rhythmic pattern generating network. Brain Res 848:35-44.
Maynard DM, Dando MR. 1974. The structure of the stomatogastric neuromuscular system in Callinectes sapidus, $\mathrm{Ho}$ marus americanus and Panulirus argus (decapoda crustacea). Philos Trans R Soc Lond [Biol] 268:161-220.

Mercer AR, Kirchhof BS, Hildebrand JG. 1996. Enhancement by serotonin of the growth in vitro of antennal lobe neurons of the sphinx moth Manduca sexta. J Neurobiol 29:49-64.

Moody WJ. 1998a. Control of spontaneous activity during development. J Neurobiol 37:97-109.

Moody WJ. 1998b. The development of voltage-gated ion channels and its relation to activity-dependent development events. Curr Top Dev Biol 39:159-185.

Mooney RD, Crnko-Hoppenjans TA, Ke M, Bennett-Clarke CA, Lane RD, Chiaia NL, Rhoades RW. 1998. Augmentation of serotonin in the developing superior colliculus alters the normal development of the uncrossed retinotectal projection. J Comp Neurol 393:84-92.

Persico AM, Altamura C, Calia E, Puglisi-Allegra S, Ventura R, Lucchese F, Keller F. 2000. Serotonin depletion and barrel cortex development: impact of growth impairment vs. serotonin effects on thalamocortical endings. Cereb Cortex 10:181-191.

Pulver SR, Marder E. 2002. Neuromodulatory complement of the pericardial organs in the embryonic lobster, Homarus americanus. J Comp Neurol, to appear.

Richards KS, Marder E. 2000. The actions of crustacean cardioactive peptide on adult and developing stomatogastric ganglion motor patterns. J Neurobiol 44:31-44.

Richards KS, Miller WL, Marder E. 1999. Maturation of the rhythmic activity produced by the stomatogastric ganglion of the lobster, Homarus americanus. J Neurophysiol 82:2006-2009.

Spitzer NC. 1994. Spontaneous $\mathrm{Ca}^{2+}$ spikes and waves in embryonic neurons: signaling systems for differentiation. Trends Neurosci 17:115-118.

Spitzer NC, Ribera AB. 1998. Development of electrical excitability in embryonic neurons: mechanisms and roles. J Neurobiol 37:190-197.

Sullivan JM, Benton JL, Beltz BS. 2000. Serotonin depletion in vivo inhibits the branching of olfactory projection neurons in the lobster deutocerebrum. J Neurosci 20: $7716-7721$

Torres G, Horowitz JM, Laflamme N, Rivest S. 1998. Fluoxetine induces the transcription of genes encoding c-fos, corticotropin-releasing factor and its type 1 receptor in rat brain. Neuroscience 87:463-477.

Vitalis T, Cases O, Callebert J, Launay JM, Price DJ, Seif I, Gaspar P. 1998. Effects of monoamine oxidase A inhibition on barrel formation in the mouse somatosensory cortex: determination of a sensitive developmental period. J Comp Neurol 393:169-184.

Zhang B, Harris-Warrick RM. 1994. Multiple receptors mediate the modulatory effects of serotonergic neurons in a small neural network. J Exp Biol 190:55-77. 